\title{
A ORDEM mUnDIAL E O BRICS: UMA FORMAĈ̣̃O contra hegemônICa?
}

\author{
Mara Rúbia Muniz Monteiro 27 \\ Rita de Cássia Ferreira Lins e Silva ${ }^{28}$
}

\section{RESUMO}

No plano político-normativo internacional o discurso acerca de uma ordem mundial quanto a pretensão liberal de consensos universais deve ser questionado. A hegemonia no plano mundial pode resultar na incongruência da validade de direitos ditos universais. Assim, o objetivo é analisar, a partir do modelo teórico de Jürgen Habermas e Chantal Mouffe, as proposituras do BRICs no sentido de questionar se esta unidade pode ser considerada uma força contra hegemônica ou uma composição da hegemonia liberal, que postula por consensos morais universais.

Palavras-chave: Ordem mundial. Liberalismo. Hegemonia. Contra hegemonia.

\section{INTRODUÇÃO}

A ideia de que a promessa política do liberalismo se encontra em um estágio de estabilização na ordem mundial, sendo este o sentido mais comum empregado por teóricos no âmbito das sociedades ocidentais, certamente deve ser questionado. Da teoria à prática política observa-se que os discursos relacionados à possibilidade de harmonização cultivada pela pretensão de consensos racionais universais, em verdade, mascara a imposição de concepções morais que se pretendem extensiva a toda humanidade, sem antes levar em conta

27 Doutoranda em Sociologia pela Universidade Federal do Paraná (UFPR) e Mestra em Planejamento do Desenvolvimento pela Universidade Federal do Pará (UFPA). E-mail: monteiro.mrm@gmail.com.

28 Doutoranda e Mestra em filosofia na linha de Ética e filosofia política pela Pontifícia Universidade Católica do Paraná (PUCPR). Especialista em Direitos humanos pela Universidade de São Paulo (USP) e Direito socioambiental (PUCPR). Formação em Direito pela Associação de Ensino Superior de Olinda - PE (AESO). E-mail: linsesilva@globo.com. 
as particularidades valorativas de cada sociedade. Trata-se de um quadro que representa uma conjuntura atual em que as relações internacionais ao invés de caminharem para uma democracia pluralista sofrem a constante ameaça de obstrução por novas hegemonias.

A ordem mundial democrática, aspirada em termos de um ideal de Democracia Cosmopolita, encampa a seara de discussões quanto à construção de uma hegemonia que transcende as diferentes concepções de mundo. Esta versão, no curso da história, já apresentou inúmeras resultantes - marcadamente expostas por ações violentas - nas sociedades cujos valores culturais, entre outros, foram considerados ilegítimos em face daqueles oriundos do modelo ocidental, em que o modelo de racionalidade busca pela promoção de uma verdade única estigmatizada no ideal cínico de uma paz e felicidade perpétua no mundo mágico de um cosmopolitismo fantasticamente idealizado.

O modelo cosmopolita tem como grande objetivo a universalização de direitos considerados legítimos e, portanto, válidos para todos. O que seria uma pretensão que, além de contraditória, pode ser considerada como uma ameaça, pela incongruência da validade de direitos ditos universais. O que está em jogo, então, é a abertura de novos discursos cuja frente alcance as diferentes concepções de mundo. Dito de outro modo trata-se do afastamento da farsa ideológica de uma ordem mundial pensada sob o molde cosmopolita, que pode mascarar os conteúdos valorativos e concretos no contexto do pluralismo social.

Neste sentido, importa trazer para o debate dois importantes discursos teóricos que, contrapostos, estão diretamente ligados ao tema. Trata-se do projeto de ordem mundial pluralista de Chantal Mouffe ${ }^{29}$ e do projeto de uma comunidade internacional de Jürgen Habermas ${ }^{30}$. Pretende-se analisar, a partir destas duas

29 Teórica política nascida em 1943, em Charleroi, na Bélgica, em conjunto com Ernesto Laclau, escreveu "Hegemonia e Estratégia Socialista", além de inúmeras obras de sua autoria.

Trabalha o projeto de Democracia Radical Plural, o que denomina de "pluralismo agonístico. É professora do Departamento de Política e Relações Internacionais, da Universidade de Westminster, no Reino Unido, onde dirige o Centro de Estudo da Democracia.

30 Filósofo e sociólogo alemão, Jürgen Habermas nasceu em 1929, em Düsseldorf, na Alemanha. É criticado por Mouffe em relação ao seu modelo de democracia deliberativa por postular em seu livro "Direito e Democracia: entre facticidade e validade" pretensões normativas de 
visões teóricas, as proposituras almejadas pelo grupo formado por países emergentes denominado de BRICs no plano político-normativo internacional. Sendo, pois, a partir deste recorte colocado o seguinte questionamento: no contexto da mundialização o BRICs representa a constituição de forças contra hegemônicas ou, ao contrário, a união de forças entre diferentes nações que compõem mais uma unidade da hegemonia liberal?

A ideia de uma ordem mundial pensada a partir da tomada de decisões coletivas dos Estados, como defendido pelos países do BRICs, aliado com as pretensões normativas das Organizações das Nações Unidas (ONU), ao assumirem um posicionamento de universalização dos valores ocidentais, parece incoerente com a postura dos primeiros no que se refere a um diálogo entre as diferentes civilizações no que tange aos valores culturais, religiosos, entre outros aspectos. O que significa uma diferença de povos - como exposto nas Cúpulas I, II e III. Entretanto, ao mesmo tempo em que há posicionamentos marcados por discursos em prol de uma ordem multipolar plural, observa-se o possível encaminhamento da constituição de uma comunidade internacional onde predomina a imposição mascarada pelo consenso, em que a união aparente de forças se submentem ao poder de potências com vistas à própria fortificação e posicionamento universal neste cenário. O que coloca em tela os obstáculos a uma juridificação democrática, que oscila entre a legalidade e a legitimidade no âmbito internacional.

\section{O PROJETO DE UMA COMUNIDADE INTERNACIONAL}

Desde os anos de 1980, Habermas vem dialogando com as teorias do direito e da sociologia, a resultante é a compilação da obra Democracia e direito: entre facticidade e validade. Seu discurso se amplia quando passa a tratar das condições normativas do direito no âmbito das relações internacionais. No centro

validade universal que impõe uma concepção de sujeito em termos de uma universalidade abstrata. Foi considerado um dos filósofos mais importantes do século XX. 
de seu discurso está a necessidade de reestruturação das Organizações das Nações Unidades (ONU) como entidade representativa dos direitos da humanidade.

Para o autor, a agenda política mundial não corresponde mais, em um primeiro plano, aos conflitos estabelecidos entre os Estados, mas por um novo tema:

(...) trata-se de saber se os potenciais conflitos internacionais podem ser controlados de tal modo que a partir de uma - até agora improvável cooperação das potências mundiais possam ser desenvolvidos normas e procedimentos eficazes globalmente, bem como capacidades de ação política amplamente disseminada.

A principal ideia de Habermas está na tensão entre direito e moral, que pode ser equilibrada a partir do momento em que o direito internacional seja ampliado no nível de um direito cosmopolita. Para o autor, este último somente é possível a partir de uma reestruturação das instituições jurídicas que compõe o quadro mundial capaz de constituir uma ordem regida na legalidade e na legitimidade das decisões político-normativas. Propõe, assim, que uma segunda câmara na Assembleia Geral das Nações Unidas seja criada a partir da eleição de representantes escolhidos pelos indivíduos de diferentes nações, ao lado daquela constituída por pessoas qualificadas, que continuaria como a bancada dos representantes nomeados pelos Estados. Quanto ao Conselho de Segurança, este deveria considerar os desequilíbrios de poder entre as diferentes nações e modificar os procedimentos aplicados ao campo decisório no sentido de considerar as posições assumidas majoritariamente. Perspectivas que configurariam, então, a nova caricatura do Direito Internacional. Concepções que implicam na ideia de uma transnacionalização das soberanias.

A transnacionalização da soberania implica pensar em resultantes do ponto de vista da promoção de problemas que incidem na ordem democrática. Neste sentido, Habermas expõe que o primeiro passo, então, é saber com qual significado de democracia é possível trabalhar no âmbito internacional em face da exigência de expandir as capacidades de ação política para além das fronteiras 
nacionais a partir do sentido normativo da própria democracia. ${ }^{31}$ Uma comunidade democrática internacional pautada na lógica da influência da liberdade comunicativa dos cidadãos do mundo é a chave pensada por este autor. O que implica, de um lado, na construção de procedimentos com força política legitimadora e, de outro, na inclusão dos cidadãos no acoplamento de decisões apoiadas pela maioria (qualificada) e que, por fim, reverberam na formação deliberativa da juridificação democrática.

Quanto a uma inclusão dos cidadãos do mundo, no processo político, afirma que deve envolver uma "eleição democrática, [pois que] são os únicos capazes de autorizar alguém a agir em nome de todos". ${ }^{32}$ Deste modo, um distributivo universal desta participação pressupõe que decisões sejam tomadas tendo como parâmetro a influência de coletivos. Neste caso, tendo como referência que a cultura política pode se diferenciar, as eleições são resultado, então, da formação da opinião e da vontade que alude a um ethos comum.

Para o autor, "a totalidade das gerações hoje existentes de uma humanidade espalhada pelo globo compartilhará (...) os interesses abstratos em bens básicos considerados importantes para a sobrevivência". ${ }^{33}$ Portanto, a eleição de representantes para compor uma Assembleia geral no âmbito mundial, tem como premissa que os cidadãos do mundo afirmam suas posições com base na universalização de valores compartilhados pela humanidade. Sua voz encontra eco não nos contextos específicos, mas na abstração que deve operar a política internacional, ou seja, a representação destes cidadãos do mundo deve se apoiar no sentido mesmo ao qual foram escolhidos: julgar imparcialmente as demandas que devem reger a agenda política internacional.

31 HABERMAS, Jurgen. Sobre a constituição da Europa: um ensaio. Tradução de Denilson Luis Werle, Luiz Repa e Rúrion Melo. São Paulo: Unesp, 2012. p. 92.

32

33

HABERMAS, 2012, p. 54.

HABERMAS, 2012, p. 99. 
Assim, o acoplamento entre decisões da maioria, advinda de um processo eletivo, tem como resultante a composição de uma Assembleia geral de representantes dos cidadãos e dos Estados. Sendo, pois, a Organização das Nações Unidas (ONU) considerada como locus principal das atividades deliberativas na ordem mundial. A sua representação é equivalente a uma espécie de Estado Mundial. ${ }^{34}$

Conforme Habermas, dito de outro modo, a formação deliberativa da juridificação democrática, que tem correspondência estreita com o processo eletivo, é onde se devem considerar as bases legais para a política e para o direito na jurisdição global, bem como os limites normativos de políticas internas no âmbito transnacional. Também a imposição global, igual e efetiva, de proibição da violência, e a proteção de populações contra governos criminosos através de intervenções.

A resposta habermasiana a tensão entre a suposição de um paradoxo entre legitimidade (validade) a partir da legalidade (facticidade), contempla sua perspectiva de possibilidade da função estabilizadora do direito. Neste contexto, tem autoridade o corpo da ONU. Decerto, para o autor, os argumentos em prol da legitimidade do direito devem ser compatíveis com os princípios morais de justiça e solidariedade universal.

Estes pontos se firmam na principal noção lançada por Habermas, o princípio do discurso (D): "são válidas as normas de ação às quais todos os possíveis atingidos poderiam dar o seu assentimento, na qualidade de participantes de discursos racionais". Segue-se que o princípio moral resulta de uma especificação do princípio do discurso para normas de ação que possam ser justificadas tendo em vista uma relação simétrica de interesses. Na linha da teoria do discurso o princípio moral assume um sentido universalista $(U)$ de validade das regras (morais).

34 Cf. HABERMAS, Jurgen. A inclusão do outro: estudos de teoria política. Tradução de George Sperber e Paulo Astor Soethe. São Paulo: Loyola, 2002, p. 199. 
O princípio do discurso se fundamenta nas relações simétricas de reconhecimento inscritas nas formas de vida comunicativamente estruturadas. A validade de uma norma de ação decorre do reconhecimento de pretensões de validade - por todos os possíveis atingidos. Assim, os discursos racionais são passíveis de problematizações. Deve-se considerar que tal princípio pressupõe que questões práticas podem ser julgadas imparcialmente e decididas racionalmente.

A fundamentação desse pressuposto se dá através de uma teoria da argumentação, que conduz à distinção entre os diversos tipos de discurso (e de negociações). Para cada um desses tipos de discurso, o julgamento imparcial deverá mostrar quais são as regras que permitem uma resposta a problemas (questionamentos) pragmáticos, éticos ou morais. Em que estas regras de argumentação operacionalizam o princípio do discurso. ${ }^{35}$

Estes procedimentos serviriam como base às construções referentes às decisões político-normativas alçadas pelos representantes de diferentes nações que compõem o quadro daquela considera como principal e legítima organização capaz de interceder nos conflitos estabelecidos mundialmente: a ONU. A proposta é a edificação de consensos racionais possíveis de serem articulados universalmente e aceitos como legítimos. O que Habermas parece tomar como crença é o fato de que todo conflito é passível de ser resolvido harmoniosamente, já que postula a ideia de que todas as formas de vida, estruturadas comunicativamente, possuem interesses e valores que, em certo ponto, podem ser considerados lineares.

A partir destes pressupostos em é compreensível o posicionamento de Habermas em razão da suposição de que seria possível, como no caso de Kosovo, pensar uma forma de intervenção pacífica. Entretanto, as críticas da esquerda europeia remetidas ao autor se devem ao fato de sua defesa quanto às fundamentações morais das intervenções em prol de um discurso humanitário. $O$

35 HABERMAS, Jurgen. Direito e Democracia: entre facticidade e validade. Vol. 1. Tradução de Flávio Beno Siebeneicher. Rio de Janeiro: Tempo Brasileiro, 1997. p. 148. 
que repercutiu fortemente na ideia de que Habermas se afasta da vertente marxista e passa a assumir um posicionamento liberal europeu. Assim sendo, o autor expõeum pensamento projetado para um mundo unificado, que aponta para posicionamentos teóricos tradicionais como sendo o guardião de uma racionalidade capaz de superar os conflitos a partir de uma ordem que pode ser considerada como hegemônica. O que no plano internacional, na leitura habermasiana, significa dizer que a hegemonia é tratada em termos de uma cooperação entre as nações do ocidente, no sentido de que estas, ao possuírem um potencial econômico e político de influência mundial, possuem os recursos necessários para dialogarem e decidirem na nova ordem mundial, liderada pela ONU, as regras político-normativas que devem reger a humanidade. Trata-se da realização de discursos e negociações racionalmente formulados e que resultariam em consensos universais morais racionais.

\section{O PROJETO DE ORDEM MUNDIAL PLURALISTA}

A crença liberal na globalização e na universalização da democracia vem antecipar um cosmopolitismo que coloque em xeque os "inimigos da liberdade", e resguarde ao mundo, direitos (abstratos) correspondentes a toda a humanidade. Sendo, pois, esta perspectiva presente em Habermas e criticada por Mouffe. Suas argumentações repousam nas consequências da negação do antagonismo, se opondo às vertentes liberais que postulam a possibilidade de um consenso racional universal. A autora levanta as diversas formas com as quais o liberalismo se apresenta, mas afirma que:

(...) todas elas compartilham uma premissa comum: que a forma de vida ocidental é a melhor e que o progresso moral exige sua implementação em todo o mundo. Este é o universalismo liberal que visa impor suas instituições para o resto do mundo com o argumento de que elas são as únicas racionais e legítimas. ${ }^{36}$

\footnotetext{
36 MOUFFE, Chantal. Democracia, cidadania e a questão do pluralismo. Tradução de Kelly
} Prudêncio. Política \& Sociedade, n.3, p. 11-26. Out. 2003. 
Com estas considerações a autora reafirma a incapacidade do liberalismo em reconhecer, adequadamente, a natureza pluralista do mundo social. $\mathrm{O}$ que se deve ao teor abstrato que envolve a validade de direitos na ordem mundial, possibilitado por pretensão normativas universais consensuais, mediante procedimentos supostamente imparciais, cujo sentido está na reconciliação de interesses e valores em prol da defesa da humanidade. Mouffe expõe que "a tarefa dos teóricos e políticos democráticos deveria consistir em promover a criação de uma esfera pública vibrante de luta "agonista", onde podem confrontarse diferentes projetos políticos (...). ${ }^{37}$

A democracia liberal se constitui por formas sedimentadas de relações de poder que incorrem em intervenções hegemônicas que se manifestam em imposições de valores não necessariamente compartilhados por todos os povos do mundo. Assim, a autora discorre sobre a necessidade de formações contra hegemônicas, ou seja, a composição de unidades políticas no plano internacional que confrontem os preceitos morais considerados legítimos por um bloco de países, como os Estados Unidos e aqueles que compõem a União Europeia, e que atuem de forma contestatória. Trata-se, de uma desarticulação das práticas existentes, juntamente com a criação de novos discursos e instituições.

Para Mouffe, o obstáculo principal do enfoque liberal está na convicção de que "depois do colapso do modelo soviético, tem-se testemunhado a hegemonia (in) discutida do neoliberalismo, com sua afirmação de que não existe alternativa a ordem existente". ${ }^{38}$ Com este discurso se observa, no contexto político-normativo das relações internacionais, o registro da moralidade no sentido da moralização da política. Para ilustrar este quadro se toma como referência os discursos proferidos pelos Estados Unidos, sobretudo, desde o "11 de Setembro" - marcado pelas frases de George W. Bush, de eliminar os "inimigos da liberdade".

37 MOUFFE, Chantal. En torno a lo político. Traducción de Soledad Laclau. Buenos Aires: Fondo de Cultura Econômica, 2009. p. 11. 
A partir do momento em que os conflitos são marcados por registros morais, e não políticos, o perigo está na polarização entre o que pode ser considerado como "mundo civilizado" e os "inimigos da liberdade". O conceito de humanidade a que disto deriva pode ser proclamada muito mais como arma ideológica. Contra seu oponente, potências se utilizam do termo no sentido de identificar seus valores como sendo representantes de toda humanidade e, neste sentido, suas intervenções se apoiam na sua defesa, mascarando suas reais intenções.

Trata-se aqui de uma hegemonia supostamente global que transparece na equiparação de interesses e valores particulares com suas normas morais que se pretendem universalmente impostas. A oposição aos interesses e valores considerados universalmente válidos por um grupo de potências que se acham representantes da humanidade, pode ser considerada como a expressão de um inimigo que deve ser domesticados ou eliminado.

Contra este posicionamento, Mouffe recorre a uma relação Nós/Eles ${ }^{39}$ sublinhada pela concepção de agonismo. A relação Nós/Eles, tradicionalmente descrita como amigo/inimigo, é lida a partir da noção de conflito entre adversários, se distanciando da ideia de que ao questionar os valores, interesses e a própria identidade política social do oponente que ameaça sua existência a ação possível é a eliminação do mesmo (registro moral da política). Entretanto, ressalve-se que o sentido de adversário empregado por Mouffe se distancia daquela pensado pelos liberais. Sobre isto, afirma a autora:

Para os liberais, um adversário é simplesmente um competidor. O campo da política constitui para ele um terreno neutro no qual diferentes grupos competem para ocupar as posições de poder; seu objetivo é meramente derrotar outros com o fim de ocupar o seu lugar. Não questionam a hegemonia dominante, e não tem, uma intenção de transformar profundamente as relações de poder. É simplesmente uma competência entre elites. O que está em jogo na luta agonista, ao contrário, é a

\footnotetext{
39 Carl Schmitt, jusfilófo e cientista político, em sua obra 'The concept of the political' traça as ideias acerca da dimensão do político configurado na relação Nós/Eles (amigo/inimigo). Esta concepção é relida por Mouffe na tradução de um nós/eles em que o 'Eles' não conduz a uma concepção de inimigo, mas de adversário. Cf. SCHMITT, Carl. The concept of the political. New Brunswick: Rutgers, 1976.
} 
configuração mesma das relações de poder em torno das quais se estrutura uma determinada sociedade. ${ }^{40}$

Esta interpretação permite, então, conceber a política democrática a partir de uma concepção plural agonista. O que é impensável no âmbito de modelos racionalistas que tendem a desconsiderar a diversidade. ${ }^{41}$ Medida que compreende considerarmos a existência de diferentes unidades políticas, em que os objetos demandados por estas unidades não podem ser lidos como imutáveis, tampouco considerados como algo passível de ser generalizado. Justamente porque a unidade não representa a totalidade, pois a sua própria existência se faz possível pela existência de outras, as quais podem não compartilhar dos mesmos valores ou interesses. Uma razão para repensar as medidas consideradas no âmbito das intervenções e da própria construção do direito no nível internacional.

Ao lado desta interpretação agonista da democracia Mouffe traz a ideia de hegemonia ${ }^{42}$, não mais no sentido clássico empregado por Gramsci, ${ }^{43}$ mas como prática articulatória cujo sentido está nas possibilidades de desarticular a ordem existente para instaurar outra forma de hegemonia (contra hegemônica). Trata-se do estabelecimento de uma nova hegemonia, que implica em uma cadeia de equivalências entre a diversidade de lutas democráticas. ${ }^{44} \mathrm{~A}$ ampliação deste

\footnotetext{
$40 \quad$ MOUFFE, 2009, p. 28.

$41 \quad$ Cf. MOUFFE, 2003, p. 88.
}

$42 \quad$ Ao lado de Ernesto Laclau, Chantal Mouffe tece as principais considerações acerca de um projeto hegemônico na obra de ambas intitulada 'Hegemony and Socialist Strategy', que sintetiza a visão destes autores quanto à Democracia radical plural. Cf. LACLAU, Ernesto; MOUFFE, Chantal. Hegemony and socialist strategy: Towards a Radical Democracy. London: Verso, 1985.

43 Mouffe parte da essência do conceito de hegemonia pensado por Gramsci, entretanto afirma não se tratar de uma hegemonia em termos de submissão de uma sociedade ou classe em relação à outra. Assim, Mouffe descarta o conceito de hegemonia enquanto domínio de uma classe social sobre outras e introduz o conceito de hegemonia como sinônimo de contra hegemonia. Ou seja, a união entre determinadas sociedades em oposição à submissão imposta por outras. Para exemplificar este conceito, pode-se citar, por exemplo, a hegemonia entre países do oriente, com seus padrões, regras e valores, em oposição àqueles que são considerados como legítimos entre as nações do ocidente. Uma formação contra hegemônica contraposta ao poderio hegemônico dos preceitos morais do ocidente. 
sentido pode ser remetida para novas organizações formadas no nível internacional, e que podem se posicionar frente às demais organizações de forma contra hegemônica, caso se posicione em prol de um pluralismo democrático. 0 que supõe a não equivalência entre as sociedades, mas o reconhecimento da alteridade que constitui cada uma delas.

Entretanto, a dificuldade está em que, desde o fim da guerra fria, com a massificação do modelo neoliberal de globalização, as possibilidades de construção de modelos políticos alternativos àquele imposto pelo ocidente são reduzidas. A razão disto está, sobretudo, no fato de que as organizações internacionais são controladas, direta ou indiretamente, pelo poderio enraizado no ocidente e liderado pelos Estados Unidos. Assim, a ausência efetiva de participação no sistema internacional de indivíduos e grupos - especialmente aqueles considerados ilegítimos - dificulta a construção de um quadro políticonormativo em uma ordem mundial, pois o comando de organizações como a ONU não encontra obstáculo em impor os valores e interesses reduzidos de potências. Neste sentido, é que se deve pensar a importância quanto à formação de grupos contra hegemônicos, capazes de fazer frente ao império do poder que há tempos aterroriza a humanidade. De tal modo, para Mouffe:

Atualmente, a situação na arena internacional é similar em muitos
aspectos ao que assinala antes a propósito da política nacional: a
ausência de um pluralismo efetivo congela a possibilidade de que os
antagonismos podem encontrar formas de expressão legítima agonistas,
ou seja, legítimas. (...). O problema, mais uma vez, é a negação da
dimensão do político, e a ideia de que o objetivo da política - seja em
nível nacional ou internacional - é estabelecer consenso em torno de um
único modelo, impedindo assim a possibilidade de um dissenso legítimo.
45

Assim, na perspectiva de se posicionar contra os discursos cosmopolitas, Mouffe discorre sobre a necessidade de reconhecer a natureza pluralista do mundo argumentando em favor de uma ordem mundial multipolar. Um desafio plantado frente à crença liberal quanto a sua superioridade moral, que tem como

$45 \quad$ MOUFFE, 2009, p. 89. 
proposta central "reformar as Nações Unidas e incrementar o poder das instituições judiciais internacionais, a fim de assegurar a primazia da lei sobre a força e o exercício do poder." ${ }^{46}$ Nesta conjuntura, a autora acredita que a restrição de potências unidas, que formam organizações internacionais como a ONU, reduz o processo de decisões político-normativas entre grupos de interesse intervenientes nas questões particulares, muitas vezes de forma violenta e desumanamente arbitrária.

Para a construção de um projeto multipolar é necessário abandonar, primeiramente, "a ilusão de um mundo unificado". ${ }^{47}$ Aceitar, ainda, o multilateralismo em um mundo multipolar que requer a existência de uma pluralidade de centros de decisão. Uma dinâmica de pluralização constituída na ordem global com base em diferentes blocos regionais autônomos, e que tenham voz ativa no sistema de direito internacional:

Acredito que deveríamos almejar o estabelecimento de uma ordem
mundial pluralista onde um grande número de unidades regionais
coexistam, com suas culturas e valores diferentes, onde uma pluralidade
de compreensões dos "direitos humanos" e formas de democracia seriam
consideradas legítimas.

Sob o ponto de vista de Mouffe, instituições que regulam as relações internacionais deveriam incorporar 0 pluralismo inerente às sociedades constitutivas da ordem mundial. Uma única estrutura unificada de potências que assume a posição de uma "soberania mundial", como a ONU, dentre outras organizações internacionais, deve ser questionada. Os objetivos da ONU, como facilitadora no processo de cooperação no âmbito do direito, da segurança, do desenvolvimento econômico e do progresso social internacional devem ser questionados em face de sua formação. Pois muito embora seja composta por diversos Estados soberanos, o poder, de fato, no que concerne ao contexto das

\footnotetext{
46

MOUFFE, 2009, p. 98.

47

MOUFFE, 2009, p. 123.

48

MOUFFE, 2003, p. 25.
} 
decisões, está na articulação reduzida de poucas potências - a começar pelo questionamento que se coloca frente à localização de suas principais sedes.

Assim, o posicionamento de Mouffe, ao contrário daquele proferido por Habermas, está na possibilidade de formação de novos grupos que se expressem politicamente no plano internacional, pelo reconhecimento quanto à legitimidade de de seus mundos potencialmente plurais e reais. Tais formações deveriam compor entidades como a ONU, na edificação de forças contra-hegemônicas que se manifestam em oposição àquelas forças hegemônicas que formam usualmente o cenário de decisões político-normativas no plano mundial. Neste caso o projeto de uma ordem multipolar pretende confrontar os discursos, para que se alcance 0 reconhecimento no campo da validade de direitos. O que impõe colocar em xeque a universalidade de pretensões político-normativas, pois cada sociedade é formada por uma cultura, valores e interesses específicos que não podem ser considerados no momento de intervenções propagadas por organizações internacionais em prol de interesses econômicos e geopolíticos de potências hegemônicas.

\section{ENTRE A HEGEMONIA E A CONTRA HEGEMONIA: O "BRICS"}

A formação de novos grupos de representatividade internacional como o BRICs (Brasil, Rússia, Índia China e, recentemente, África do Sul), tem grande repercussão quanto às possibilidades de novas alternativas não somente no âmbito econômico, mas no direito internacional em face da precariedade das instituições atuais. A expectativa é, justamente, a inserção dos países membros com poder efetivo na agenda da política internacional, que colaborem para a construção de novos modelos jurídicos compatíveis com a realidade plural das sociedades que integram a ordem mundial.

De acordo com Maria Fontenele Reis, "o início do século XXI passou a explicitar de modo contundente o que o Brasil (e outros países) apontava há décadas - a falta de representatividade e, portanto, de legitimidade das 
instituições internacionais gestadas no pós-guerra". ${ }^{49}$ Para além da expressão da representatividade de cada país membro, o BRICs tem sido apontado como nova possibilidade de representação, uma nova estrutura de poder que mudaria a perspectiva pela qual o mundo é percebido. Dito com outras palavras, e tomando como referência os apontamentos de Mouffe, poderia significar um centro de influência na estrutura multipolar de poder. Entretanto, há os discursos daqueles que acreditam que o BRICs acabará, ou se aliará aos interesses do ocidente na busca de influência política. O que significa aliar-se aos interesses providos de valores morais liberais, ou seja, uma composição da hegemonia liberal no plano mundial.

No documento da Cúpula I que compila o comunicado conjunto dos líderes dos países do BRIC (Brasil, Rússia, Índia China), em 2009, tem-se o anúncio quanto ao apoio de uma "ordem mundial multipolar mais democrática e justa baseada no respeito ao direito internacional, igualdade, respeito mútuo, cooperação, ação coordenada e tomada de decisões coletivas por todos os Estados". ${ }^{50}$ Um esforço político e diplomático cujo fim está na busca de soluções pacíficas quanto às controvérsias que se estabelecem nas relações internacionais. ${ }^{51}$ De acordo com Maria Fontenele Reis:

(...) o surgimento dos BRICs compõem um novo mecanismo políticodiplomático que se constitui em um momento de redesenho da governança global, em que se torna cada vez mais aguda a percepção do déficit de representatividade $e$, portanto, de legitimidade, das estruturas gestadas no pós-guerra. ${ }^{52}$

Para Maria Soares de Lima, o BRICs, no contexto dos conflitos internacionais, está inscrito no processo de transição do momento unipolar para

\footnotetext{
49 REIS, Maria E. Fontenele. BRICS: surgimento e evolução. In. O Brasil, os BRICs e a agenda internacional. Brasília: Funag, 2012. p. 36.

50

51

52

REIS, 2012, p. 33.
} 
um ordenamento difuso do poder mundial. ${ }^{53}$ Entretanto, reforça que há uma grande especulação quanto à possibilidade de uma possível cooptação com a ordem liberal. Assim, suas proposições não buscariam, necessariamente, uma efetiva mudança na ordem institucional existente, mas antes a busca de autoridade e status nela. ${ }^{54}$

O compromisso mantido com a diplomacia multilateral da Organização das Nações Unidas anunciado nas Cúpulas (I, II e III) com ênfase na necessidade de reforma da ONU frente aos desafios globais, no sentido de reiterar a sua participação efetiva nas questões internacionais juntamente com a afirmação quanto aos intentos de ações em prol de diálogos entre civilizações, culturas, religiões e povos parece, em princípio, contradizer tal perspectiva. ${ }^{55}$ Entretanto, ao reforçarem o apoio a uma "Aliança de Civilizações", parece questionável os seus intentos na medida em que tal aliança sugere a formação de consensos político-normativos que teriam como prescrição as pretensões de ordem moral aceitas como válidas pelas potências que dominam a ONU. O que tem par com os pressupostos lançados por Habermas, ou seja, de que a possibilidade de novas composições no cenário mundial estaria escalada por potencias que tenham, de fato, uma estrutura de influência na ordem mundial.

No mesmo sentido, a Cúpula III anuncia a contribuição para o desenvolvimento da humanidade e estabelecimento de um mundo justo e equânime. O que leva a uma indagação acerca dos parâmetros que serão utilizados para o cumprimento desta promessa.

Na Cúpula II, o delineamento de suas intenções resta claro:

53 Cf. LIMA, Maria Regina Soares de; COSTELAN, Daniel Ricardo. O Brasil, os BRICS e a institucionalização do conflito internacional. In. O Brasil, os BRICs e a agenda internacional. Brasília: Funag, 2012. p. 176.

54

55

Cf. LIMA; COSTELAN, 2012, p. 177.

Cf. BRASIL. Comunicado conjunto dos líderes dos países BRIC. Cúpula II. Itamaraty, 2010; . Comunicado conjunto dos líderes dos países BRIC. Cúpula III. Itamaraty, 2011. 
Destacamos que a presença simultânea dos cinco países do BRICS no Conselho de Segurança durante o ano de 2011 oferece valiosa oportunidade de se trabalhar de forma conjunta e estreita sobre questões de paz e segurança, com vistas a reforçar as abordagens multilaterais e a facilitar futura coordenação sobre temas da agenda do Conselho de Segurança da ONU. Manifestamos nossa profunda preocupação com a turbulência no Oriente Médio, no Norte e no Oeste da África e desejamos sinceramente que os países afetados alcancem paz, estabilidade, prosperidade e progresso e que recuperem sua posição e sua dignidade no mundo de acordo com as legítimas aspirações de seus povos. Compartilhamos o princípio de que o uso da força deve ser evitado. Afirmamos que a independência, a soberania, a unidade e a integridade territorial de cada nação devem ser respeitadas. Desejamos dar continuidade a nossa cooperação no Conselho de Segurança das Nações Unidas sobre a questão na Líbia. Concordamos que todas as partes devem resolver suas divergências por meios pacíficos e pelo diálogo com a ONU e organizações regionais competentes desempenhando os papéis que Ihes cabem. Expressamos igualmente apoio ao Painel de Alto Nível da União Africana sobre a Líbia. Reiteramos nossa firme condenação ao terrorismo em todas suas formas e manifestações e enfatizamos não haver justificativa alguma a quaisquer atos de terrorismo. Acreditamos que as Nações Unidas têm papel central na coordenação de ações internacionais contra o terrorismo, de acordo com a Carta das Nações Unidas e em conformidade com os princípios e normas do direito internacional. Nesse contexto, instamos a rápida conclusão das negociações, no âmbito da Assembleia Geral da ONU, da Convenção Global sobre Terrorismo Internacional e sua adoção por todos os Estados-Membros. Estamos determinados a reforçar nossa cooperação na luta contra essa ameaça global. ${ }^{56}$

Desta feita, uma dúvida, entre várias, é lançada: quem dita os parâmetros do que pode ser compreendido como legítimo e o que constitui uma ameaça global? Assim, é necessário reafirmar, no contexto da política internacional, mais especificamente quando se toma como referência o fim da ordem mundial bipolar, que a tendência de um mundo harmonioso não se concretizou, ao contrário, é a intensificação de novos antagonismos que marca o campo de suas intervenções. Entretanto, o que está em jogo é se novas formações, como o BRICs, podem ser capazes de se lançar como forças contra hegemônicas, ou simplesmente atuar em pacto com as hegemonias dominantes.

\section{CONCLUSÃO}


Com o colapso do comunismo as possibilidades de se pensar o direcionamento para uma democracia pluralista cessa na medida em que novos antagonismos surgem, tal como os conflitos étnicos, religiosos, nacionalistas, que são tratados pela agenda internacional pela nominação de "inimigos da humanidade". Este teor deve ser motivo direto de questionamento ao pretenso discurso universalista que supõe que 0 progresso humano requer 0 estabelecimento de uma unidade mundial representativa, como a ONU. Um significado moral universal e suas condições de realização, aplicados na prática pelas Nações Unidas, permite afirmar a incoerência de ações de intervenções com a constituição de um mundo plural. É preciso despertar, como orienta Mouffe, do sonho de uma ocidentalização e ter a consciência de que a universalização dos valores ocidentais somente conduzirá há mais episódios de violências.

A reestruturação das instituições jurídicas certamente deve ocorrer. Entretanto, parece inegável que se a formação do quadro que compõe atualmente as organizações internacionais permanecer inalterável, a perspectiva de uma mudança radical de alcançar a ideia de uma ordem mundial multipolar, compatível com a pluralidade do mundo social, encontrará obstáculos. A possibilidade proposta por Habermas de uma câmara na Assembleia Geral das Nações Unidas, a partir da eleição de representantes escolhidos pelos indivíduos de diferentes nações, e também a ideia de que o Conselho de Segurança deve considerar os desequilíbrios de poder entre as diferentes nações, é uma alternativa a ser considerada, mas isto não é tudo.

Nesta conjuntura, face ao conturbado cenário internacional, o BRICs emerge como uma esperança para repensar a nova ordem global. A capacidade de influência e decisão de seus países membros está na balança das discussões. Tomando por base as considerações de Mouffe, poderia representar uma formação contra hegemônica capaz de fazer frente ao poderio hegemônico que impera em organizações internacionais como a ONU. A composição entre diferentes países, com suas distintas regras e valores, representaria a possibilidade de especulação prática de uma ordem mundial multipolar nos 
moldes de um projeto hegemônico, de não submissão, pensado teoricamente pela autora. Uma força contra hegemônica que eclodiria como meio de desarticulação das práticas dominantes existentes.

As proposições do BRICs e a própria constelação que marca a heterogeneidade do grupo demonstram os caminhos contrários ao pensamento de um mundo unificado. Uma possibilidade de redirecionamento nas relações internacionais quanto à incorporação de alternativas que podem enfraquecer a estrutura unificada de potências que assumem a posição de uma "soberania mundial".

Em princípio, é possível vislumbrar as proposições do BRICs como uma formação contra hegemônica, caso mantenha um discurso em prol das especificidades de cada cultura, alinhado à ideia de que existem diferentes versões acerca das sociedades e, ainda, no que concerne a dignidade humana, ao invés de recorrer a falsos universalismos. Este é o intento de uma ordem multipolar ao qual, teoricamente, se alinham. O que impõe às propostas universalistas o cuidado com os valores, crenças e posturas assumidas pelo pensamento crítico de cada povo no que se refere a uma formação política de suas próprias normas. Trata-se de um limiar extremamente delicado existente entre a pretensão de um mundo conciliado e de um mundo que possa se mover criticamente em prol de seus valores.

Entretanto, também é necessário destacar a incongruência de seus discursos ao reforçarem o apoio a uma "Aliança de Civilizações", que sugere partir de pretensões político-normativas morais universais consolidadas consensualmente pelas potências que dominam a ONU, reafirmando a possibilidade de uma composição da hegemonia liberal. Tem-se ainda que os discursos acerca da paz e da justiça colocam algumas interrogações acerca de quais parâmetros serão utilizados para defini-los e alcançá-los. Quando se analisa os conteúdos expostos nas Cúpulas é possível perceber contradições quanto ao posicionamento do BRICs em relação à constituição de uma formação multipolar, 
e que podem indicar um interesse em aliar-se aos intentos das potencias hegemônicas que dominam o cenário mundial.

$\mathrm{Na}$ fase embrionária de suas posições, é difícil caracterizar as intenções e repercussões das possíveis ações do BRICs, mas é possível vislumbrar mudanças nas regras e normas vigentes no plano da política-normativa internacional que o grupo pode alçar, lançando desequilíbrios necessários entre a ordem e o poder nas instituições internacionais.

\section{REFERÊNCIAS}

BRASIL. Comunicado conjunto dos líderes dos países BRIC. Cúpula I. Itamaraty, 2009.

Itamaraty, 2010.

. Comunicado conjunto dos líderes dos países BRIC. Cúpula II.

Comunicado conjunto dos líderes dos países BRIC. Cúpula III. Itamaraty, 2011.

HABERMAS, Jurgen. Direito e Democracia: entre facticidade e validade. Vol. 1. Tradução de Flávio Beno Siebeneicher. Rio de Janeiro: Tempo Brasileiro, 1997.

A inclusão do outro: estudos de teoria política. Tradução de George Sperber e Paulo Astor Soethe. São Paulo: Loyola, 2002.

. Sobre a constituição da Europa: um ensaio. Tradução de Denilson Luis Werle, Luiz Repa e Rúrion Melo. São Paulo: Unesp, 2012.

LIMA, Maria Regina Soares de; COSTELAN, Daniel Ricardo. O Brasil, os BRICS e a institucionalização do conflito internacional. In. O Brasil, os BRICs e a agenda internacional. Brasília: Funag, 2012.

MOUFFE, Chantal. Democracia, cidadania e a questão do pluralismo. Tradução de Kelly Prudêncio. Política \& Sociedade, n.3, p. 11-26. Out. 2003.

. En torno a lo político. Traducción de Soledad Laclau. Buenos Aires: Fondo de Cultura Econômica, 2009.

REIS, Maria E. Fontenele. BRICS: surgimento e evolução. In. O Brasil, os BRICs e a agenda internacional. Brasília: Funag, 2012. 
v. I. A. I. fev 2013 - ARtIGos 